\title{
What did COVID-19 Change? The Impact of COVID-19 on Korean Parents' and Children's Daily Lives and Stress
}

\author{
Joo-hyang Park ${ }^{1} \cdot$ Ji-young Park ${ }^{1} \cdot$ Kyong-sun Jin $^{1}[\mathbb{D}$
}

Received: 26 April 2021 / Accepted: 23 September 2021 / Published online: 1 October 2021

(c) The Author(s), under exclusive licence to Springer Science+Business Media, LLC, part of Springer Nature 2021

\begin{abstract}
The COVID-19 outbreak has not only posed a threat to physical health but has also changed our daily lives. This study explored how the COVID-19 pandemic affected Korean parents' and children's daily lives and stress levels. Parents' childcare time, children's screen time, the time spent for social interactions and learning, and parents' and children's stress levels before and after the pandemic were compared. The main caregivers' childcare time increased significantly during the pandemic $(4.00 \mathrm{~h} /$ day $)$. For children, the time spent for screen time $(1.76 \mathrm{~h})$ and online interactions $(0.95 \mathrm{~h})$ increased significantly, whereas face-to-face interaction time $(4.17 \mathrm{~h})$ and time spent learning $(2.16 \mathrm{~h})$ decreased significantly. In addition, parents' and children's stress levels increased significantly during the pandemic. Other descriptive information is provided and discussed. Our results indicate that Korean parents and children experienced significant disruption to their daily lives and increased stress during the pandemic.
\end{abstract}

Keywords COVID-19 $\cdot$ Parenting $\cdot$ Children $\cdot$ Social distancing $\cdot$ Daily lives $\cdot$ Stress

\section{Introduction}

In December 2019, a cluster of pneumonia cases was reported by the Wuhan Health Commission, China [1]. The novel disease causing this outbreak, coronavirus disease 2019 (COVID-19), soon became a global pandemic. Many countries implemented restrictions on population movement and social interaction to slow the spread of COVID-19. For example, Italy and China conducted lockdowns throughout the country [2], Brazil [3] and the United States (U.S.) implemented stay-at-home campaigns [4], and South Korea set five levels of social distancing rules and banned private gatherings of five or more people [5].

Although public health actions were taken globally to mitigate COVID-19 contagions, these actions also resulted in unintended consequences that impacted family life. In April 2020, in more than 167 nations, at least 1.46 billion children (83.8\% of enrolled learners) were out of childcare or school, without access to group activities, social interactions, or team sports [6]. To date, parents and caregivers in

Kyong-sun Jin

kyongsun.jin@gmail.com

1 Department of Psychology, Sungshin Women's University, 2, Bomun-ro 34-da gil, Seongbuk-gu, Seoul 24844, Korea many countries continue to work from home or are unable to work, while caring for their young children, without knowing how long the pandemic will last. For parents, keeping children busy and safe at home or transitioning to homebased learning can be a daunting prospect. For children, staying home for longer hours than usual, with limited social interactions or learning online, can be a demanding task.

A growing body of research has suggested that parents in many countries have experienced and continue to deal with increased parenting stress during COVID-19 [7, 8]. In the U.S., for example, parents have reported higher levels of stress than adults without children [9]. More than $70 \%$ of parents have reported that managing their children's online education and daily routines is stressful [9]. Similarly, Japanese parents have reported increased stress levels after their children's school closure [10]. In Italy, the pandemic has led to parental emotional exhaustion [11], especially in mothers. The worsening of parents' psychological health, such as increased levels of stress or anxiety, could lead to harsher parenting and negative consequences for their children's well-being $[7,8,12,13]$.

Few studies have explored the impact of the COVID-19 pandemic on children's daily lives or psychological health $[14,15]$. Children have experienced significant disruptions to their daily routines, with daycare and school closures in 
many countries. As children are confined to home during the pandemic, they may suffer with delicate physical health, loneliness, anxiety, and boredom [8,16-18]. Research has suggested that children have much longer screen times, irregular sleep patterns, and less favorable diets during even short periods of time away from school, for example on weekends or summer vacations $[19,20]$, which may lead to additional vulnerabilities in children's development.

Given the novelty of the COVID-19 situation, more research is needed to investigate how the COVID-19 pandemic and related social distancing practices affect parents' and children's daily lives and their psychological health. The purpose of the present study was to capture a snapshot of the impact of the unexpected shift in the daily lives of Korean parents' and their children, as well as their associated stress levels during COVID-19. In Korea, in March 2020, all daycares, kindergartens, and schools nationwide delayed opening after winter vacation and were temporarily closed until late May [21]. Schools gradually reopened from late May starting from G12 (senior high school), but soon again shutdown with the onset of a new wave of COVID19. The present study was conducted in May 2020, at which point many children remained at home.

A primary goal of the present study was to explore the impact of the COVID-19 pandemic on parents' and children's daily lives, focusing on the time they spent on various daily activities. Although research suggests that parenting stress increased during the pandemic [10, 22, 23], it is unclear as to how much the childcare burden (with respect to time spent in this regard) increased during this time. Therefore, we quantified the increased parenting burden during the pandemic by asking parents to recall the average hours per day they spent on childcare before and after the onset of the pandemic. We hypothesized that the time spent by parents on childcare per day significantly increased during versus before the pandemic. Regarding children, it is still unclear as to how the COVID-19 pandemic has changed their daily activities. Therefore, we measured the average time spent by children engaged in various activities (e.g., screen time, learning, and face-to-face and online social interactions) before and after the onset of the pandemic. We hypothesized that the time spent by children in face-to-face social interactions, and on learning, significantly decreased, whereas the screen time and time spent on other forms of social interactions significantly increased, after versus before the onset of the pandemic.

In addition, we explored the change in stress levels of parents and children during the pandemic. Although recent research has initiated investigations into individuals' stress during the pandemic [24, 25], few studies have addressed the changes in parents' and children's stress levels. This is because there are practical limitations in obtaining baseline data of these stress levels before the COVID-19 pandemic.
The present study sought to compare parents' and children's stress levels before and after the onset of the pandemic, although less ideal, by asking parents to recall their stress levels at the two time points. We hypothesized that parents' and children's stress levels increased after the pandemic. In addition, the present study investigated the main stressors and the activities that parents and children relied on to cope with their stress.

The objective of the present study was to explore the effects of the COVID-19 pandemic and related socialdistancing practices on family life, the childcare burden on parents, and children's daily lives, with a focus on the early stage of the pandemic in South Korea. The study also evaluated the negative impact of the COVID-19 pandemic on parents and children's stress levels. We believe that the findings of the present study will provide useful information to better understand how the COVID-19 pandemic has affected parents' and children's daily lives, and how families continue to cope with the pandemic situation in their daily lives.

\section{Method}

\section{Participants and Procedures}

A total of 296 Korean adults completed the survey; of these, 8 (3\%) were eliminated because they did not meet the criterion of being the main caregiver of at least one child aged between 1 and 12 years. The final sample included 288 parents, with at least one child aged 1-12 years who was living at home. Table 1 summarizes the characteristics of the participants (92\% mothers and $8 \%$ fathers). In total, $53.9 \%$ of the participants were employed and $45.1 \%$ were unemployed, housewives or househusbands. Approximately $63.1 \%$ of the participants had incomes below the average monthly household income (\$3750) reported in the South Korean consensus (https://kosis.kr/eng/) of the second quarter of 2020.

If participants had multiple children, they were asked to report about their youngest child. The mean age of the participants' youngest child was 5.56 years (standard deviation [SD] 3.31 years; range $1-12$ years). The average number of family members was $3.70(S D=0.87)$, and the average number of children was $1.70(S D=0.70)$. In terms of family structure, $91.7 \%$ of the families were nuclear families, and $7.6 \%$ of the families were extended families.

Participants were recruited through social media (i.e., a survey link with instructions posted on Instagram) and online parenting forums [i.e., Naver (www.naver.com) online cafés for parents]. The online survey was conducted on the Survey Monkey platform, between May 24 and May 28, 2020. The survey took approximately $20 \mathrm{~min}$ to complete. Participants were compensated with a coffee coupon after 
Table 1 Participant characteristics $(N=288)$

\begin{tabular}{|c|c|c|}
\hline & $N$ & $\%$ \\
\hline \multicolumn{3}{|l|}{ Participant gender } \\
\hline Male & 23 & 8.0 \\
\hline Female & 265 & 92.0 \\
\hline \multicolumn{3}{|l|}{ Participant occupation } \\
\hline Employed & 155 & 53.9 \\
\hline Housewife or househusband & 130 & 45.1 \\
\hline Student & 3 & 1.0 \\
\hline \multicolumn{3}{|l|}{ Monthly household income (\$) } \\
\hline$<1800$ & 88 & 30.6 \\
\hline $1800-3599$ & 94 & 32.6 \\
\hline $3600-5400$ & 56 & 19.4 \\
\hline $5401-7200$ & 25 & 8.7 \\
\hline$>7200$ & 25 & 8.7 \\
\hline \multicolumn{3}{|l|}{ Family structure } \\
\hline Nuclear family (parents and children) & 264 & 91.7 \\
\hline Extended family (grandparents, parents, and children) & 22 & 7.6 \\
\hline \multirow[t]{2}{*}{ Other } & 2 & 0.7 \\
\hline & $M(S D)$ & Range \\
\hline Child age & $5.56(3.31)$ & $1-12$ \\
\hline Number of family members in the household & $3.70(0.87)$ & $2-8$ \\
\hline Number of children in the household & $1.70(0.70)$ & $1-6$ \\
\hline
\end{tabular}

completion of the survey. Each participant gave consent as they started the survey, and the protocol was approved by the Institutional Review Board of Sungshin Women's University (Seoul, South Korea).

\section{Measures}

We developed ad-hoc questionnaires to explore the changes that parents and children encountered in their daily lives due to the COVID-19 pandemic. We designed an online questionnaire to be completed by the caregivers of children during the COVID-19 pandemic. The questionnaire was simple and easy to complete. The questionnaire consisted of two main parts: one part asking about the changes in parents' childcare burden and stress and a second part that focused on changes in children's daily activities and stress.

\section{Questions About Parents: Changes in Childcare Burden and Parental Stress}

To explore parents' experiences during the pandemic, we first asked parents to select the biggest change in their daily lives since the pandemic began (e.g., problems in their physical health or that of a member of their family, child's school closure, governmental order for self-quarantine, changes in household income, etc.). Parents were also asked to report the biggest concern regarding their physical health (e.g., decrease in exercise, weight gain, poorer sleep, etc.) and psychological health (e.g., nervousness, lethargy, depression, anxiety, fear of death, etc.). For the multiple-choice questions used in the survey, participants could choose only one option; however, they were also provided with the opportunity to enter a free-response option if none of the existing choices represented their situation.

Next, to quantify the increased childcare burden due to the pandemic, we asked participants to recall the average number of hours per day that they and other adult(s) of the same household spent on childcare at two time points, before and after the onset of the pandemic. Childcare time was defined as the time spent by the participants, or other adults in the same household, on childcare, i.e., on caring for and educating their children. Regarding the time spent on childcare after the onset of the pandemic, we asked the participants to report their experience during the past week. In addition, parents reported their stress level before and after the onset of the pandemic on a five-point scale. To further describe the nature of the changes in parental stress, we asked parents to select the most significant factor that they felt had affected the change in their stress level (e.g., staying at home for a much longer time than usual, keeping socially distant, childcare burden, etc.), and how they attempted to relieve their stress (e.g., engaging in indoor 
or outdoor activities, social interactions, using electronic devices, etc.) before and during the pandemic.

\section{Questions About Children: Changes in Children's Daily Activities and Stress}

For children, parents were asked to report about their youngest child. Similar to the questions about the parents themselves, we first asked parents to select the change in their child's daily life that they were currently most concerned about (e.g., longer screen time, decrease in social interactions, decrease in physical activities, changes in sleep or meal patterns, etc.). Parents also reported the most significant concern regarding their child's physical health (e.g., decrease in exercise, weight gain, difficulty with sleep, etc.) and psychological health (e.g., lethargy, depression, anxiety, fear of death, etc.).

Next, to quantify the changes in the time children spent on their daily activities, we asked participants to report the average number of hours per day on weekdays that their child stayed at home and spent their time as screen time, social interactions (face-to-face or online), and learning, before and after the onset of the pandemic. As with the parent-focused section of the questionnaire, parents were asked to report their child's stress level before and after the onset of the pandemic on a five-point scale. We also asked parents to select the most significant factor that they thought had affected the change in their child's stress level (e.g., staying at home for a much longer time than usual, keeping socially distant, challenges of online classes, etc.), and the way their child relieved stress (e.g., engaging in indoor activities, outdoor activities or social interactions, using electronic devices, etc.) before and during the pandemic. Finally, we asked parents to report on their child's positive experiences during COVID-19.

\section{Results}

The collected data were analyzed using descriptive statistics and a paired sample $t$-test.

\section{Changes in Parents' Childcare Burden and Stress due to COVID-19}

\section{Descriptive Results}

Table 2 presents the descriptive results for the biggest change in parents' own life after COVID-19, the biggest concerns about parents' own physical and psychological health, the main cause of parental stress, and the main way parents' relieved stress before and after the onset of COVID-19. Most parents $(81.9 \%)$ reported the closure of their child's daycare, kindergarten, or school as the most significant change in their daily lives after the onset of the pandemic. Regarding the concerns about parents' own physical health, they reported a decrease in physical exercise (42.4\%) and weight gain (31.3\%) as the biggest concerns. Regarding the concerns about parents' own psychological health, they reported nervousness (35.4\%) and lethargy $(24.0 \%)$ as the biggest concerns.

\section{Childcare Before and After the Onset of COVID-19}

The average number of hours per day that parents spent on childcare increased significantly after the onset of the pandemic (before: mean $[M]=6.43 \mathrm{~h}, S D=3.43$; after: $M=10.43, S D=4.05$ ), $t(287)=19.22, p=0.000$ (Fig. 1). Indeed, most parents $(n=264,91.7 \%)$ reported an increase in the time spent on childcare after the onset of the pandemic. Similarly, 251 parents lived with other adult(s) at home, and all of them (100\%) reported an increase in the childcare hours of other adult(s) in the same household. The average hours per day that other adult(s) spent on childcare also increased significantly after the onset of the pandemic (before: $M=3.71, S D=3.47$; after: $M=4.94, S D=4.04$ ), $t(250)=5.66, p=0.000$. In sum, during the pandemic, primary caregivers were providing about 4.00 additional hours of childcare per day, and other household members were performing about 1.23 additional hours of childcare per day.

\section{Parents' Stress Before and After the Onset of COVID-19}

Parents reported that their stress level after the onset of the pandemic $(M=4.17, S D=0.76)$ was significantly higher than that before the pandemic $(M=3.30, S D=0.77$; $t(287)=17.08, p=0.000$; Fig. 2). Regarding the most significant factor that affected parents' stress, more than one third of parents reported having to stay at home for much longer times than usual (43.1\%) and having to remain socially distant $(37.1 \%)$ as the main causes for their stress (Table 1). Before the pandemic, parents engaged in face-to-face social interactions with their friends (31.3\%) or outdoor activities (25.7\%) and used electronic devices such as smartphones or computers (19.4\%) to relieve their mental stress. After the pandemic, however, using electronic devices (46.9\%) became the most popular way for parents to relieve their own stress, followed by online social interactions with their friends (17.4\%) and indoor activities (17.4\%).

\section{Changes in Children's Daily Life and Stress due to COVID-19}

\section{Descriptive Results}

Table 3 presents the descriptive results of the change in children's daily life during COVID-19 that parents were 
Table 2 Descriptive results of the biggest change in parents' daily lives after COVID-19, the biggest concerns in parents' physical and psychological health, the main cause of parents' stress, and the main way parents relieved stress before and after COVID-19 $(N=288)$

\begin{tabular}{|c|c|c|}
\hline & $n$ & $\%$ \\
\hline \multicolumn{3}{|l|}{ The biggest change in parents' own life } \\
\hline Child's school closure & 236 & 81.9 \\
\hline Changes in household income & 23 & 8.0 \\
\hline Problems with the physical health of themselves or their family & 10 & 3.5 \\
\hline In quarantine & 8 & 2.8 \\
\hline Other & 11 & 3.8 \\
\hline \multicolumn{3}{|l|}{ The biggest concern regarding parents' own physical health } \\
\hline Decrease in physical exercise & 122 & 42.4 \\
\hline Weight gain & 90 & 31.3 \\
\hline Difficulty with sleep & 32 & 11.1 \\
\hline Poorer vision due to excessive use of electronic devices & 17 & 5.9 \\
\hline Digestive problems & 11 & 3.8 \\
\hline Other & 16 & 5.6 \\
\hline \multicolumn{3}{|l|}{ The biggest concern regarding parents' own psychological health } \\
\hline Nervousness & 102 & 35.4 \\
\hline Lethargy & 69 & 24.0 \\
\hline Loneliness due to limited social interactions & 55 & 19.1 \\
\hline Anxiety & 29 & 10.1 \\
\hline Depression & 26 & 9.0 \\
\hline Fear of death & 2 & 0.7 \\
\hline Other & 5 & 1.7 \\
\hline \multicolumn{3}{|l|}{ The main cause of parents' own stress } \\
\hline Staying at home for a much longer time than usual & 124 & 43.1 \\
\hline Keeping socially distant & 107 & 37.1 \\
\hline Extra burden of helping child with online classes & 45 & 15.6 \\
\hline Other & 12 & 4.2 \\
\hline \multicolumn{3}{|l|}{ Before the pandemic: the main way parents relieved their own stress } \\
\hline Face-to-face interactions with friends & 90 & 31.3 \\
\hline Outdoor activities & 74 & 25.7 \\
\hline Using electronic devices & 56 & 19.4 \\
\hline Online interactions with friends & 26 & 9.0 \\
\hline Indoor activities & 22 & 7.6 \\
\hline Sleep & 14 & 4.9 \\
\hline Other & 6 & 2.1 \\
\hline \multicolumn{3}{|l|}{ After the pandemic: the main way parents relieved their own stress } \\
\hline Using electronic devices & 135 & 46.9 \\
\hline Online interactions with friends & 50 & 17.4 \\
\hline Indoor activities & 50 & 17.4 \\
\hline Sleep & 21 & 7.3 \\
\hline Outdoor activities & 20 & 6.9 \\
\hline Face-to-face interactions with friends & 3 & 1.0 \\
\hline Other & 9 & 3.1 \\
\hline
\end{tabular}

most concerned about, the biggest concerns regarding their child's physical and psychological health, the main cause of the child's stress, the main way to relieve the child's stress before and after the onset of COVID-19, and the child's positive experiences during COVID-19. More than one third of parents $(34.4 \%)$ reported an increase in their child's screen time as the change that they were most concerned about, followed by a decrease in social interactions (19.1\%) and a decrease in physical activity (18.1\%). Regarding concern about their child's physical health, parents reported a decrease in physical exercise $(42.0 \%)$ and decrease in visual acuity due to excessive use of electronic devices $(21.5 \%)$ as their biggest concerns. Regarding parents' concerns about their child's psychological health, they reported loneliness 


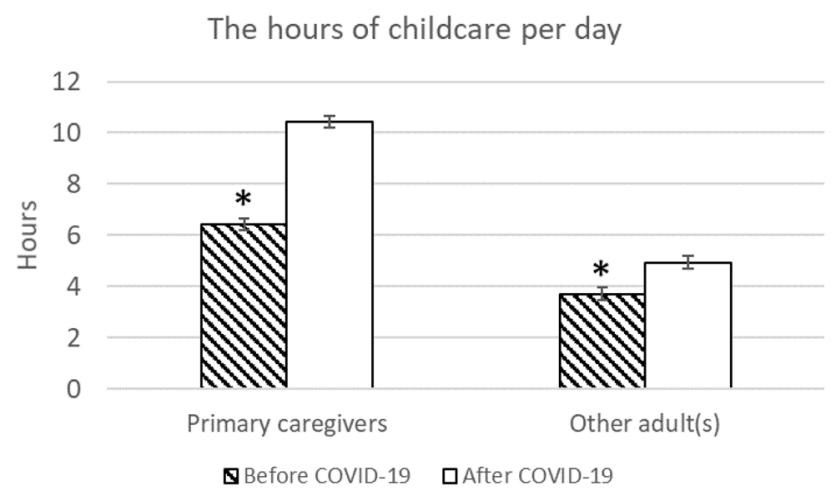

Fig. 1 Average hours per day primary caregiver $(n=288)$ and other adults $(n=251)$ spent on childcare before and after the onset of COVID-19. Errors bars represent standard error, and asterisks denote a significant difference between the two time points $(p<.05)$

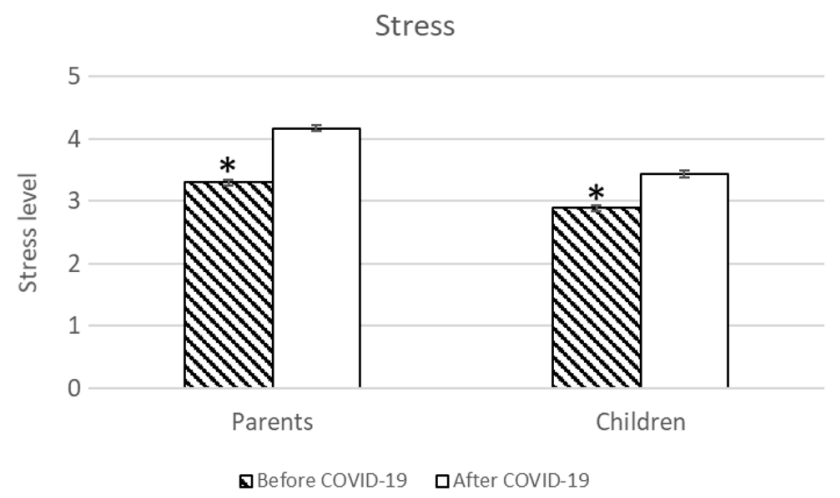

Fig. 2 Average stress level of parents and their child before and after the onset of the pandemic $(N=288)$. Errors bars represent standard error, and asterisks denote a significant difference between the two time points $(p<.05)$

due to limited social interactions (46.9\%) and lethargy (18.4\%) as the biggest issues. Despite challenges due to the pandemic, parents also reported that their child had positive experiences. Specifically, parents reported that their child was getting sufficient rest while staying at home (43.4\%) and was spending more time with family $(32.3 \%)$.

\section{Children's Activities Before and After the Onset of COVID-19}

Parents reported that the average number of hours per day on weekdays that children stayed at home increased significantly during the pandemic (before: $M=14.51 \mathrm{~h}, S D=$ 5.19; after: $M=20.42, S D=5.22)$. Regarding the time children spent on various activities, parents reported an increase in their child's screen time per day after the pandemic (before: $M=2.20, S D=1.84$; after: $M=3.96, S D=$ 2.28), $t(287)=16.41, p=0.000$ (Fig. 3). In terms of children's social interactions, the average number of hours of children's face-to-face interactions on weekdays decreased significantly (before: $M=5.78, S D=2.69$; after: $M=1.61$, $S D=2.51 ; t(287)=-21.20, p=0.000)$, whereas the average number of hours of online interactions increased significantly (before: $M=1.96, S D=2.83$; after: $M=2.91, S D$ $=4.16 ; t(287)=4.31, p=0.000)$. In addition, the average number of hours that children spent learning on weekdays decreased significantly after the pandemic (before: $M=5.63$, $S D=2.94$; after: $M=3.47, S D=2.41 ; t(287)=-12.67$, $p=0.000)$. We conducted correlational analyses to explore further the relationships between the difference in primary caregivers' childcare time and the differences in the time that children spent on various activities. These additional analyses determined that the difference in primary caregivers' childcare time was significantly correlated with the difference in the child's screen time $(r=0.22, p=0.000)$ and the difference in the time that children spent on face-to-face interactions $(r=-0.16, p=0.003)$ and learning $(r=-0.13$, $p=0.03)$. These correlation results suggest that the sudden decrease in caregiver availability during the pandemic could be related to how children allocate their time among the various activities in their daily lives.

\section{Children's Stress Before and After the Onset of COVID-19}

Parents reported that their child's stress level increased significantly after the pandemic (before: $M=2.89, S D=0.78$; after: $M=3.43, S D=0.88 ; t(287)=10.37, p=0.000$; Fig. 2). Regarding the main cause of children's stress, parents reported staying at home for a much longer time than usual as the most significant factor (45.5\%) affecting their child's stress level during the pandemic, followed by keeping socially distant $(40.6 \%)$ and challenges with online classes. Before the pandemic, children engaged in outdoor activities (35.1\%) or face-to-face social interactions with their friends (27.8\%), and used electronic devices such as smartphones or computers (16.3\%) to relieve their mental stress. After the pandemic, however, electronic devices (47.6\%) became the most popular way for children to relieve their own stress, followed by indoor activities (27.8\%).

\section{Discussion}

The present study investigated the changes experienced by Korean children and their parents after the onset of the COVD-19 crisis, focusing on parents' concerns about their own health and their child's health, parenting burden, child's daily activities, and parents' and children's stress. The results described parents' main concerns regarding their own physical and mental health and that of their youngest child. Regarding physical health, parents were concerned most about the decrease in physical activity for themselves 
Table 3 Descriptive results of the change in children's daily lives during COVID-19 that parents were most concerned about, the biggest concerns regarding the child's physical and psychological health, the main cause of the child's stress, the main way to relieve the child's stress before and after COVID-19, and the child's positive experiences during COVID-19 $(N=288)$
(20)

The change in their child's daily life that parents were most concerned about

Longer screen time

99

$\%$

Decrease in social interactions

Decrease in physical activities

19.1

Changes in sleep patterns

18.1

Changes in meal patterns

15.3

Fear of COVID-19

6.6

Boredom

Other

The biggest concern regarding the child's physical health

Decrease in physical exercise

42.0

Poorer vision due to excessive use of electronic devices

Weight gain

13.9

Difficulty with sleep

12.5

Digestive problems

Other

The biggest concern regarding the child's psychological health

Loneliness due to limited social interactions

Lethargy

18.4

Nervousness

17.4

Difficulties with learning

Anxiety

Depression

2.1

Fear of death

The main cause of the child's stress

Staying at home for a much longer time than usual $\quad 131 \quad 45.5$

Keeping socially distant

Challenges with online classes

Other

Before the pandemic: the main way of relieving the child's stress

Outdoor activities

Face-to-face interactions with friends

Using electronic devices

16.3

Indoor activities

12.8

Online interactions with friends

Sleep

0.3

Other

After the pandemic: the main way of relieving the child's stress

Using electronic devices

47.6

Indoor activities

27.8

Outdoor activities

10.1

Online interactions with friends

6.6

Face-to-face interactions with friends

Sleep

Other

Child's positive experiences during COVID-19

Getting enough rest

Spending more time with family

Child did not have any positive experiences

Development of independence

Development of the ability to cooperate with others 
Table 3 (continued)

\begin{tabular}{lcc}
\hline & $n$ & $\%$ \\
\hline Emotional development & 6 & 2.1 \\
Other & 9 & 3.1 \\
\hline
\end{tabular}

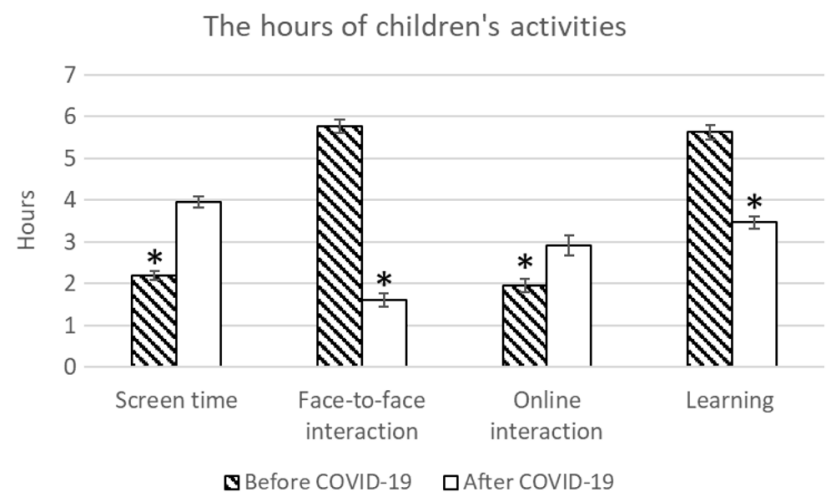

Fig. 3 Average hours per day children spent on screen time, face-toface interactions, online interactions, and learning before and after the onset of COVID-19 $(N=288)$. Errors bars represent standard error, and asterisks denote a significant difference between the two time points $(p<.05)$

and their child. Parents were concerned most about nervousness and lethargy for their mental health. For their child's mental health, parents were most concerned about loneliness due to limited social interactions and lethargy. These results together describe and specify parents' concerns about the physical and mental health of their family during the COVID-19 pandemic.

The present study provides a snapshot of how families with children were adapting to COVID-19 early in the pandemic (i.e., May 2020). Notably, $81.9 \%$ of the parents in the present study said that the closure of their child's school was the biggest change in their daily lives. This unusual situation significantly increased the child care burden of parents. Parents who were the main caregivers performed 4.00 additional hours of childcare per day during the ongoing pandemic. Other adults in the household performed 1.23 additional hours of childcare per day. Future research may examine the relationships between additional childcare time during the pandemic and perceived parenting stress. This question is important because an increase in parenting stress is a key predictor of parenting behavior [26], and especially harsh parenting may lead to child maltreatment [27].

Parents in the present study reported that their child was spending 1.76 additional hours of screen time per day during the pandemic. These results confirmed prior findings that child screen time increased during the COVID-19 pandemic [28-31]. The increase in child screen time during COVID-19 may support claims that longer screen times are related to limited parental resources or access to childcare [32, 33]. In the present study, the difference in parents' childcare time was significantly correlated with the difference in the child's screen time. Similarly, a recent study conducted in the U.S. during COVID-19 reported that the timeline of the rise in children's screen time closely followed that of the sudden decrease in caregiver availability [29]. These results together suggest that the rise in screen time during the COVID-19 pandemic may be somewhat inevitable and driven by insufficient caregiver availability.

How much of the relationship between child screen time and negative outcomes can be explained by childcare burden remains a question. Many studies have shown that increased screen time of children is related to poor sleep, asthenopia, obesity, and other negative outcomes in their physical health [34-36]. Furthermore, child screen time is inversely associated with children's psychological health $[37,38]$ and academic performance [39]. However, it is unclear whether child screen time causes such negative developmental outcomes because increased screen time is associated with other factors that limit parental resources or access to childcare, such as low socioeconomic status, poor parents' mental health, and low social support for parents, and these factors are associated with poor developmental outcomes [40-43]. It is possible that such factors cause both increased screen time and negative outcomes or the factors and increased screen time jointly cause negative outcomes $[32,33]$. The unfortunate pandemic situation provides researchers with a unique opportunity to investigate how the sudden increase in childcare burden and child screen time are related, and how they affect child developmental outcomes [29].

The strength of the present study is that it documents how much the COVID-19 pandemic has affected children's realworld social life and learning in terms of time (hours). In the present study, children spent 4.17 fewer hours in face-to-face offline interactions. Although children used video chat or social media to interact with others for 0.95 additional hours per day during the pandemic, this does not appear to compensate for the drastic decrease in children's social interactions. The results also suggest that COVID-19 has impacted children's learning. In the present study, children spent 2.16 fewer hours learning per day during the COVID-19 pandemic. Taken together, these results provide useful information to quantify the "adverse consequences of school closure" [34] during COVID-19. Future studies should include follow-up measures to investigate in more detail the longitudinal effects of social distancing and lockdown on children's psychosocial development and educational outcomes. 
Consistent with previous findings [10,35], parents in the present study reported that their stress level had increased significantly during the COVID-19 pandemic. In addition, the present study provides novel evidence that parents' perceived level of their child's stress also increased during the pandemic. As noted in the study, COVID-19 also changed the kinds of activities that parents and children engaged in to relieve their mental stress. Before the pandemic, parents and children participated in outdoor activities or social interactions to ameliorate their stress. During the pandemic, however, both parents and children relied on electronic devices or indoor activities to relieve their stress. The focal point of future research should be in developing interventions or effective coping strategies that could be implemented under such lockdown situations.

This study had several limitations. First, all measures in this study were reported by parents; thus, all study results are the parents' perceptions. For example, we asked parents to report their child's stress level and use the measures to estimate the children's stress. We do not have data from more objective measures to verify and validate the results. Second, the present study is cross-sectional in nature. For the questions that asked about factors before and after the pandemic, parents were required to recall two time points in the past. Although we did so to measure the baselines of various factors before the pandemic, we do not know the reliability of the parents' recall. All of the study results should be interpreted with these caveats in mind. Third, the survey was relatively short because we wanted to limit the burden on the participants. In particular, certain key variables, such as childcare burden (time spent caring for children per day) and stress, were measured in a simple manner. In future studies, we plan to investigate whether the pandemic has affected the time spent on active versus passive childcare [36]. We also plan to monitor the stress levels of caregivers using validated scales completed at various time points during the pandemic. Fourth, despite our efforts to include a representative sample, there may have been a degree of selection bias; the sample only included parents who had access the internet and were willing to answer questions online. Also, because we did not collect data for certain demographic variables (such as parents' education and age), the possibility that the sample was not representative of the general population cannot be excluded. Future studies should systematically investigate the factors that affect parental stress and children's well-being during the ongoing COVID-19 pandemic. We plan to investigate these issues in a larger sample, and to collect more detailed data on parents' socioeconomic status.

Regardless, the results provide evidence that the COVID-19 pandemic significantly disrupted the daily lives of Korean parents' and their children and that parents and children are experiencing more stress in this novel situation. As the pandemic continues into 2021, these impacts continue to accumulate and become exacerbated. There is a pressing need for longitudinal studies and to implement innovative solutions to cater to the psychosocial and mental health needs of parents and children during and after the pandemic.

\section{Summary}

This study was one of the first to report changes in the daily lives of parents and children during the COVID-19 pandemic, specifically in the time spent engaged in various activities. The results suggest that the time spent on childcare by the main caregivers increased significantly (to $4.00 \mathrm{~h}$ per day) during the early stages of the pandemic (characterized by social distancing and school closures). Children's daily lives were also significantly affected by the pandemic, during which the time spent using screens $(1.76 \mathrm{~h})$, and engaging in online interactions $(0.95 \mathrm{~h})$, significantly increased. In contrast, the time spent in face-to-face interactions $(4.17 \mathrm{~h})$, and on learning $(2.16 \mathrm{~h})$, significantly decreased. Furthermore, parents' and children's stress levels significantly increased during the pandemic. Exploratory analyses suggested that spending more time than usual at home was the most significant factor in parents' and children's increased stress levels. During the pandemic, parents and children were most likely to use electronic devices and participate in indoor activities as a means of relieving stress. This study provides useful data for researchers and practitioners pertaining to changes in the lives of parents and children that occurred during the COVID-19 pandemic. The data could also provide a basis for future research.

Author Contributions $\mathrm{JP}^{1}$, $\mathrm{JP}^{2}$, and $\mathrm{KJ}$ designed the research; $\mathrm{JP}^{1}$ and $\mathrm{JP}^{2}$ performed the research; $\mathrm{JP}^{1}$ and $\mathrm{KJ}$ analyzed the data; and $\mathrm{JP}^{1}, \mathrm{JP}^{2}$, and $\mathrm{KJ}$ wrote the paper.

Funding This research was supported by the Sungshin Women's University Research Grant of 2020.

Data Availability The data are available in an online repository hosted by the Open Science Framework (https://osf.io/axkfq/).

Code Availability Not applicable.

\section{Declarations}

Conflict of interest The authors declare no conflict of interest.

Ethical Approval All procedures performed in this study involving human participants were in accordance with the ethical standards of the institutional and/or national research committee, as well as the 1964 Declaration of Helsinki and its later amendments or comparable ethical standards. 
Consent to Participate Informed consent was obtained from all participants involved in the study.

\section{References}

1. World Health Organization [WHO] (2021) Coronavirus disease (COVID-19) weekly epidemiological update and weekly operational update. https://www.who.int/emergencies/diseases/novelcoronavirus-2019/situation-reports. Accessed 30 Sept 2021

2. Ren X (2020) Pandemic and lockdown: a territorial approach to COVID-19 in China, Italy and the United States. Eurasian Geogr Econ 61:423-434. https://doi.org/10.1080/15387216.2020.17621 03

3. Simões e Silva AC, Oliveira EA, Martelli H Jr (2020) Coronavirus disease pandemic is a real challenge for Brazil. Front Public Health 8:268. https://doi.org/10.3389/fpubh.2020.00268

4. Moreland A, Herlihy C, Tynan MA et al. CDC Public Health Law Program; CDC COVID- 19 Response Team, Mitigation Policy Analysis Unit (2020) Timing of state and territorial COVID-19 stay-at-home orders and changes in population movementUnited States, March 1-May 31, 2020. MMWR Morb Mortal Wkly Rep 69(35): 1198-1203. https://doi.org/10.15585/mmwr. mm6935a2

5. The Ministry of Health and Welfare of South Korea (2021) Social distancing basic rules. http://ncov.mohw.go.kr/socdisBoardView. do?brdId=6\&brdGubun=1. Accessed 26 April 2021

6. UNESCO (2020) Global monitoring of school closures caused by COVID-19. https://en.unesco.org/covid19/educationresponse\# schoolclosures. Accessed 22 April 2021

7. Chung G, Lanier P, Wong PYJ (2020) Mediating effects of parental stress on harsh parenting and parent-child relationship during coronavirus (COVID-19) pandemic in Singapore. J Fam Violence. https://doi.org/10.1007/s10896-020-00200-1

8. Lee SJ, Ward KP, Chang OD, Downing KM (2021) Parenting activities and the transition to home-based education during the COVID-19 pandemic. Child Youth Serv Rev 122:105585. https:// doi.org/10.1016/j.childyouth.2020.105585

9. American Psychological Association [APA] (2020) Stress in America 2020: stress in the time of COVID-19, vol 1. American Psychological Association, Washington, DC

10. Hiraoka D, Tomoda A (2020) The relationship between parenting stress and school closures due to the COVID-19 pandemic. Psychiatry Clin Neurosci 74(9):497-498. https://doi.org/10.1111/ pcn. 13088

11. Marchetti D, Fontanesi L, Mazza C, Di Giandomenico S, Roma P, Verrocchio MC (2020) Parenting-related exhaustion during the Italian COVID-19 lockdown. J Pediatr Psychol 45(10):11141123. https://doi.org/10.1093/jpepsy/jsaa093

12. Fontanesi L, Marchetti D, Mazza C, Di Giandomenico S, Roma P, Verrocchio MC (2020) The effect of the COVID-19 lockdown on parents: a call to adopt urgent measures. Psychol Trauma Theory Res Pract Policy 12(S1):S79-S81. https://doi.org/10.1037/tra00 00672

13. Patrick SW, Henkhaus LE, Zickafoose JS, Lovell K, Halvorson A, Loch S, Davis MM (2020) Well-being of parents and children during the COVID-19 pandemic: a national survey. Pediatrics 146:e2020016824. https://doi.org/10.1542/peds.2020-016824

14. Kılınçel Ş, Altun FT, Nuryüz Ö, Tan E, Erzincan E, Kılınçel O, Ayaz M (2021) Effects of COVID-19 outbreak on children's mental health: a comparative study with children diagnosed and isolated from their parents. Psychiatry Investig 18(2):140-146. https://doi.org/10.30773/pi.2020.0372
15. Singh S, Roy MD, Sinha CPTMK, Parveen CPTMS, Sharma CPTG, Joshi CPTG (2020) Impact of COVID-19 and lockdown on mental health of children and adolescents: a narrative review with recommendations. Psychiatry Res 293:113429. https://doi. org/10.1016/j.psychres.2020.113429

16. Fegert JM, Vitiello B, Plener PL, Clemens V (2020) Challenges and burden of the Coronavirus 2019 (COVID-19) pandemic for child and adolescent mental health: a narrative review to highlight clinical and research needs in the acute phase and the long return to normality. Child Adolesc Psychiatry Ment Health 14:1-11. https://doi.org/10.1186/s13034-020-00329-3

17. Jiao WY, Wang LN, Liu J, Fang SF, Jiao FY, Pettoello-Mantovani M, Somekh E (2020) Behavioral and emotional disorders in children during the COVID-19 epidemic. J Pediatr 221:264266. https://doi.org/10.1016/j.jpeds.2020.03.013

18. Loades ME, Chatburn E, Higson-Sweeney N, Reynolds S, Shafran R, Brigden A, Crawley E (2020) Rapid systematic review: the impact of social isolation and loneliness on the mental health of children and adolescents in the context of COVID19. J Am Acad Child Adolesc Psychiatry 59(11):1218-1239. https://doi.org/10.1016/j.jaac.2020.05.009

19. Brazendale K, Beets MW, Weaver RG, Pate RR, TurnerMcGrievy GM, Kaczynski AT, von Hippel PT (2017) Understanding differences between summer vs. school obesogenic behaviors of children: the structured days hypothesis. Int $\mathbf{J}$ Behav Nutr Phys Activity 14(1):1-14. https://doi.org/10.1186/ s12966-017-0555-2

20. Wang YC, Vine S, Hsiao A, Rundle A, Goldsmith J (2015) Weight-related behaviors when children are in school versus on summer breaks: does income matter? J Sch Health 85(7):458-466. https://doi.org/10.1111/josh.12274

21. Yoon Y, Kim KR, Park H, Kim S, Kim YJ (2020) Stepwise school opening and an impact on the epidemiology of COVID-19 in the children. J Korean Med Sci 35:e414. https://doi.org/10.3346/jkms. 2020.35.e414

22. Brown SM, Doom JR, Lechuga-Peña S, Watamura SE, Koppels $\mathrm{T}$ (2020) Stress and parenting during the global COVID-19 pandemic. Child Abuse Negl 110:104699. https://doi.org/10.1016/j. chiabu.2020.104699

23. Spinelli M, Lionetti F, Pastore M, Fasolo M (2020) Parents' stress and children's psychological problems in families facing the COVID-19 outbreak in Italy. Front Psychol 11:1713. https:// doi.org/10.3389/fpsyg.2020.01713

24. Charles NE, Strong SJ, Burns LC, Bullerjahn MR, Serafine KM (2021) Increased mood disorder symptoms, perceived stress, and alcohol use among college students during the COVID-19 pandemic. Psychiatry Res 296:113706. https://doi.org/10.1016/j. psychres.2021.113706

25. Kuang J, Ashraf S, Das U, Bicchieri C (2020) Awareness, risk perception, and stress during the COVID-19 pandemic in communities of Tamil Nadu, India. Int J Environ Res Public Health 17(19):7177. https://doi.org/10.3390/ijerph17197177

26. Abidin RR (1992) The determinants of parenting behavior. J Clin Child Psychol 21(4):407-412. https://doi.org/10.1207/s15374424j ccp2104_12

27. Holden EW, Banez GA (1996) Child abuse potential and parenting stress within maltreating families. J Fam Violence 11(1):1-12. https://doi.org/10.1007/BF02333337

28. Eyimaya AO, Irmak AY (2021) Relationship between parenting practices and children's screen time during the COVID-19 Pandemic in Turkey. J Pediatr Nurs 56:24-29. https://doi.org/10. 1016/j.pedn.2020.10.002

29. Hartshorne JK, Huang YT, Paredes PML, Oppenheimer K, Robbins PT, Velasco MD (2021) Screen time as an index of family distress. Curr Res Behav Sci 2:100023. https://doi.org/10.1016/j. crbeha.2021.100023 
30. Schmidt SC, Anedda B, Burchartz A, Eichsteller A, Kolb S, Nigg C, Woll A (2020) Physical activity and screen time of children and adolescents before and during the COVID-19 lockdown in Germany: a natural experiment. Sci Rep 10(1):1-12. https://doi. org/10.1038/s41598-020-78438-4

31. Xiang M, Zhang Z, Kuwahara K (2020) Impact of COVID-19 pandemic on children and adolescents' lifestyle behavior larger than expected. Prog Cardiovasc Dis 63(4):531-532. https://doi. org/10.1016/j.pcad.2020.04.013

32. Ashton JJ, Beattie RM (2019) Screen time in children and adolescents: is there evidence to guide parents and policy? Lancet Child \& Adolesc Health 3(5):292-294. https://doi.org/10.1016/ S2352-4642(19)30062-8

33. Viner R, Davie M, Firth A (2019) The health impacts of screen time: a guide for clinicians and parents. R Coll Pediatr Child Health. https://www.rcpch.ac.uk/sites/default/files/2018-12/ rcpch_screen_time_guide_-_final.pdf. Accessed 30 Sept 2021

34. UNESCO (2021) Adverse consequences of school closures. https://en.unesco.org/covid19/educationresponse/consequences. Accessed 22 April 2021

35. Achterberg M, Dobbelaar S, Boer OD, Crone EA (2021) Perceived stress as mediator for longitudinal effects of the COVID-19 lockdown on wellbeing of parents and children. Sci Rep 11(1):114. https://doi.org/10.1038/s41598-021-81720-8

36. Moro-Egido A (2012) Changing trends of mothers' active and passive childcare times. J Fam Econ Issues 33:11-23. https://doi. org/10.1007/s10834-011-9265-0

37. Cao H, Qian Q, Weng T, Yuan C, Sun Y, Wang H, Tao F (2011) Screen time, physical activity and mental health among urban adolescents in China. Prev Med 53(4-5):316-320. https://doi.org/ 10.1016/j.ypmed.2011.09.002
38. Twenge JM, Campbell WK (2018) Associations between screen time and lower psychological well-being among children and adolescents: evidence from a population-based study. Prev Med Rep 12:271-283. https://doi.org/10.1016/j.pmedr.2018.10.003

39. Adelantado-Renau M, Moliner-Urdiales D, Cavero-Redondo I, Beltran-Valls MR, Martínez-Vizcaíno V, Álvarez-Bueno C (2019) Association between screen media use and academic performance among children and adolescents: a systematic review and metaanalysis. JAMA Pediatr 173(11):1058-1067. https://doi.org/10. 1001/jamapediatrics.2019.3176

40. Johnson AD, Padilla CM (2019) Childcare instability and maternal depressive symptoms: exploring new avenues for supporting maternal mental health. Acad Pediatr 19(1):18-26. https://doi.org/ 10.1016/j.acap.2018.05.006

41. Nikken P (2019) Parents' instrumental use of media in childrearing: Relationships with confidence in parenting, and health and conduct problems in children. J Child Fam Stud 28:531-546. https://doi.org/10.1007/s10826-018-1281-3

42. Pempek TA, McDaniel BT (2016) Young children's tablet use and associations with maternal well-being. J Child Fam Stud 25:2636-2647. https://doi.org/10.1007/s10826-016-0413-x

43. Przybylski AK, Weinstein N (2019) Digital screen time limits and young children's psychological well-being: evidence from a population-based study. Child Dev 90:e56-e65. https://doi.org/ 10.1111/cdev. 13007

Publisher's Note Springer Nature remains neutral with regard to jurisdictional claims in published maps and institutional affiliations. 